\title{
Duration of Preservation of Antibodies to the Flu Virus in the Mother-Child Pairs during the Vaccination of Women Depending on the Trimester of Pregnancy
}

\author{
Mikhail P. Kostinov ${ }^{1}, \mathrm{PhD}, \mathrm{ScD}$; Alexander P. Cherdantsev ${ }^{2}, \mathrm{PhD}, \mathrm{ScD}$; \\ Anna D. Shmitko ${ }^{1}$; Dmitry V. Pakhomov ${ }^{1 *}$, PhD; Evgenia O. Demina ${ }^{1}$ \\ ${ }^{I}$ The I.I. Mechnikov Scientific-Research Institute of Vaccine and Sera, RAS; Moscow, Russia \\ ${ }^{2}$ Ulyanovsk State University; Ulyanovsk, Russia
}

\begin{abstract}
Vaccination against flu in the second and third trimesters of pregnancy with the use of Agrippal S1 is effective and meets the CPMP criteria. In our study, one month after vaccination, there was progress in the production of post-vaccination antibodies in protective values in pregnant women vaccinated in the third trimester of gestation. In neonates whose mothers had been vaccinated in the last trimester of pregnancy, there were also higher levels of protective antibodies to the flu A virus strains. Three months after childbirth, there were no significant differences in protective values of antibodies to all the strains of the flu virus in women of the compared groups. At the same time, in children born to women vaccinated in the third trimester of pregnancy, there was a significantly higher concentration of protective antibodies during the same period. Six months later, there were no transplacental antibodies in the protective values ( $\geq 1: 40$ ) among the observed children. Comparison of the levels of protective titers of antibodies to the three strains of the flu virus in the mother-infant pairs, in all the periods of observation of the children, showed significantly lower values.(Int J Biomed. 2015;5(4):179-183.)
\end{abstract}

Keywords: fu virus; vaccination of pregnant women; neonates; antibody response; hemagglutination-inhibition antibody.

\section{Introduction}

Vaccination of women against flu during pregnancy is safe and highly effective. Nevertheless, the immune response to the vaccine with regard to the trimester of gestation is poorly understood, both for the women and in regards to the passive transfer of maternal antibodies to the neonates. It can be assumed that the level and duration of preservation of the maternal post-vaccination immunity in infants are in direct proportion to their original values in mothers with normal physiological pregnancy. Vaccination in the third trimester of gestation is accompanied by a $63 \%$ decrease in the incidence of flu in neonates, and antibody titer values $\geq 1: 40$ may persist for up to 20 weeks of life [1-3]. It is also known that the best effect of maternal vaccination is observed within 42 to 50 days after birth, which coincides with the half-life of transplacental

*Corresponding author: Dmitry V. Pakhomov, PhD. Laboratory of vaccination and immunotherapy of allergic diseases, the I.I. Mechnikov Scientific-Research Institute of Vaccine and Sera, RAS; Moscow, Russia.E-mail:dm_pachomov@mail.ru antibodies to influenza virus in the infant [2]. There is a direct relation between maternal vaccination and the reduction of the flu incidence in infants during the first 2 to 3 months of life, and a $92 \%$ reduction in hospitalization of children during the first 6 months [4]. Therefore, we can conclude that vaccination during pregnancy leads to a synthesis of specific antibodies that may protect not only the vaccinated women, but also their babies during the first 3 to 5 months of life.

The aim of the study was to evaluate the levels of antibodies to the flu virus in the mother-infant pairs, taking into account the trimester of vaccination of pregnant women.

\section{Materials and Methods}

We observed 48 mother-infant pairs, which were vaccinated once with Agrippal S1 (Novartis Vaccines and Diagnostic, Italy) against flu during pregnancy in the seasons of 2010-2011 and 2011-2012.

Group 1 women $(\mathrm{n}=27)$ and Group 2 women $(\mathrm{n}=21)$ were vaccinated in the second and third trimesters of pregnancy, respectively. Observation of the women was carried out both 
during pregnancy and after childbirth, including their infants under 6 months of age. The study was carried out in accordance with the requirements of the protocol of the Ministry of Health of the Russian Federation (MoH RF) of October 2, 2009 No. $808 \mathrm{n}$ on the Approval of the Order of Rendering ObstetricGynecologic Assistance [5]. Before the vaccination, after the receipt of the informed consent of women to participate in the clinical study, a general laboratory examination was conducted (blood test, biochemical parameters, and urine test). In the absence of deviations from the normal values and in compliance with the study inclusion criteria, pregnant women were assigned to receive a vaccination against flu.

The study was conducted in accordance with established protocols, meeting the national standard of the Russian Federation [6,7]. The vaccination was conducted in compliance with the ethical standards and recommendations of the WHO and MoH RF [7,8]. The study was a single-center, prospective, randomized, open-label, comparative, parallel-group study of pregnant women and children.

Women subject to vaccination and follow-up were selected in strict compliance with the individual registration card, which was reviewed and approved by the Ethics Committee at the Institute of Medicine, Environment and Physical Education of the Ulyanovsk State University.

Over $42 / 87.5 \%$ children born to women vaccinated during pregnancy were observed. Studying the peculiarities of the early postnatal period, we also complied with the ethical requirements for conducting biomedical research on children. In drawing up the order and number of the studied parameters, we used the provisions set forth in the Order No.370 of MoH RF [9].

To evaluate the immunogenicity of the vaccine against flu in women, we conducted blood sampling before 1 and 3 months (in case of immunization in the second trimester of pregnancy) after vaccination.

Blood sampling was carried out in the mother-infant pairs on days 2 to 3 after childbirth, and at 3 and 6 months of follow-up. Serum level of the hemagglutination-inhibition antibody (HAI-Ab) was determined in HAI reaction. The antigenic activity of the vaccine was assessed in accordance with the criteria adopted by the Committee for Proprietary Medicinal Products (CPMP) [10]:

1). Seroprotection level: Percentage of vaccinated persons with the serum HAI-Ab titer higher than 1:40 on the 21 st day after vaccination (should be higher than $70 \%$ ).

2). Seroconversion rate or immunological activity of the vaccine: Percentage of vaccinated persons among all the immunoprotective people with a 4-fold or more increase in $\mathrm{HAI}-\mathrm{Ab}$ titer between baseline and by day 21 after vaccination (should be higher than $40 \%$ ).

3). Seroconversion factor or geometric mean fold rise as the geometric mean of the within-subject ratios of the postvaccination reciprocal HAI titer to the day 1 reciprocal HAI titer: geometric mean HAI antibody titers (GMTs). The ratio of GMTs before and after vaccination (GMTR) should be higher than 2.5-fold.

According to these recommendations, the vaccine is considered to be sufficiently immunogenic and effective if it meets at least one of these three criteria.

Women with HAI-Ab titer higher than 1:20 but less than 1:40 were classified as seropositive (reacting to the vaccine with a low level of the formation of specific immunity).

Statistical analysis of the obtained results was carried out using the methods of descriptive statistics (Thompson rule). The reliability of differences in the quantitative indicators of the obtained data was calculated using the nonparametric Wilcoxon test for unrelated samples (W). The sign was considered to be reliable at the values of $P<0.05$ with a confidence interval of 0.95 . We used the AtteStat 10.10.2 software package.

\section{Results}

The clinical analysis of the course of the postvaccination period in the vaccinated women in the second and third trimesters of pregnancy showed an absence of unusual events, as well as no impact of vaccination on the obstetric history.

The clinical assessment of the state of children at birth was carried out using the Apgar scale. It was discovered that 8 to 9 points were recorded in $22 / 84.6 \%$ children. A transiently reduced level of total Apgar scores (4 to 6 points), recovering to fifth minute up to 8 to 9 points, was discovered in $15.4 \%$. All the children had the physical harmony of agerelated, weight-height parameters; at the same time, we did not register significant differences in these parameters in the compared groups.

During the 6 months of life among children born to mothers of Group 1, we registered $2 / 8.7 \%$ cases of respiratory infection; as for the children born to mothers of Group 2, we registered $1 / 5.3 \%$ case $(P>0.05)$. In other words, the incidence of the acute respiratory infection of a non-flu nature was quite similar in the observed groups of infants.

One month after the vaccination in both groups of the pregnant women, the indicators of the 4-fold increase in the titers of antibodies to the flu viruses (seroconversion rate) were generally in line with the CPMP criteria (Table 1). The exception was the indicators for the $\mathrm{A} / \mathrm{H} 3 \mathrm{~N} 2$ / strain for women vaccinated in the second trimester of pregnancy $(30.4 \%)$. At the same time, a similar parameter in the vaccinated women in the third trimester had high values (72.7\%). GMTR also corresponded to the CPMP criteria with a more pronounced level for the flu viruses of the A/H3N2/ strain (9.1) and B strain (7.5) in pregnant women vaccinated in the third trimester of gestation (Table 1).

Table 1.

Seroconversion rate and factor in pregnant women depending on the trimester of vaccination against flu

\begin{tabular}{|l|c|c|c|c|c|c|}
\hline \multirow{2}{*}{ Parameter } & \multicolumn{3}{|c|}{ Group 1 } & \multicolumn{3}{c|}{ Group 2 } \\
\cline { 2 - 7 } & $\mathrm{A} / \mathrm{H} 1 \mathrm{~N} 1 / \mathrm{v}$ & $\mathrm{A} / \mathrm{H} 3 \mathrm{~N} 2 /$ & $\mathrm{B}$ & $\mathrm{A} / \mathrm{H} 1 \mathrm{~N} 1 / \mathrm{v}$ & $\mathrm{A} / \mathrm{H} 3 \mathrm{~N} 2 /$ & $\mathrm{B}$ \\
\hline $\begin{array}{l}\text { Seroconversion } \\
\text { rate (\%) }\end{array}$ & 65.2 & 30.4 & 52.2 & 72.7 & $72.7^{\circ}$ & $81.8^{\circ}$ \\
\hline $\begin{array}{l}\text { Seroconversion } \\
\text { factor }\end{array}$ & 7.9 & 3.4 & 5.2 & 8.5 & $9.1^{\circ}$ & $7.5^{*}$ \\
\hline
\end{tabular}


Table 2.

Level of seropositivity and seroprotection in the mother-child pairs depending on the trimester of vaccination of pregnant women against flu

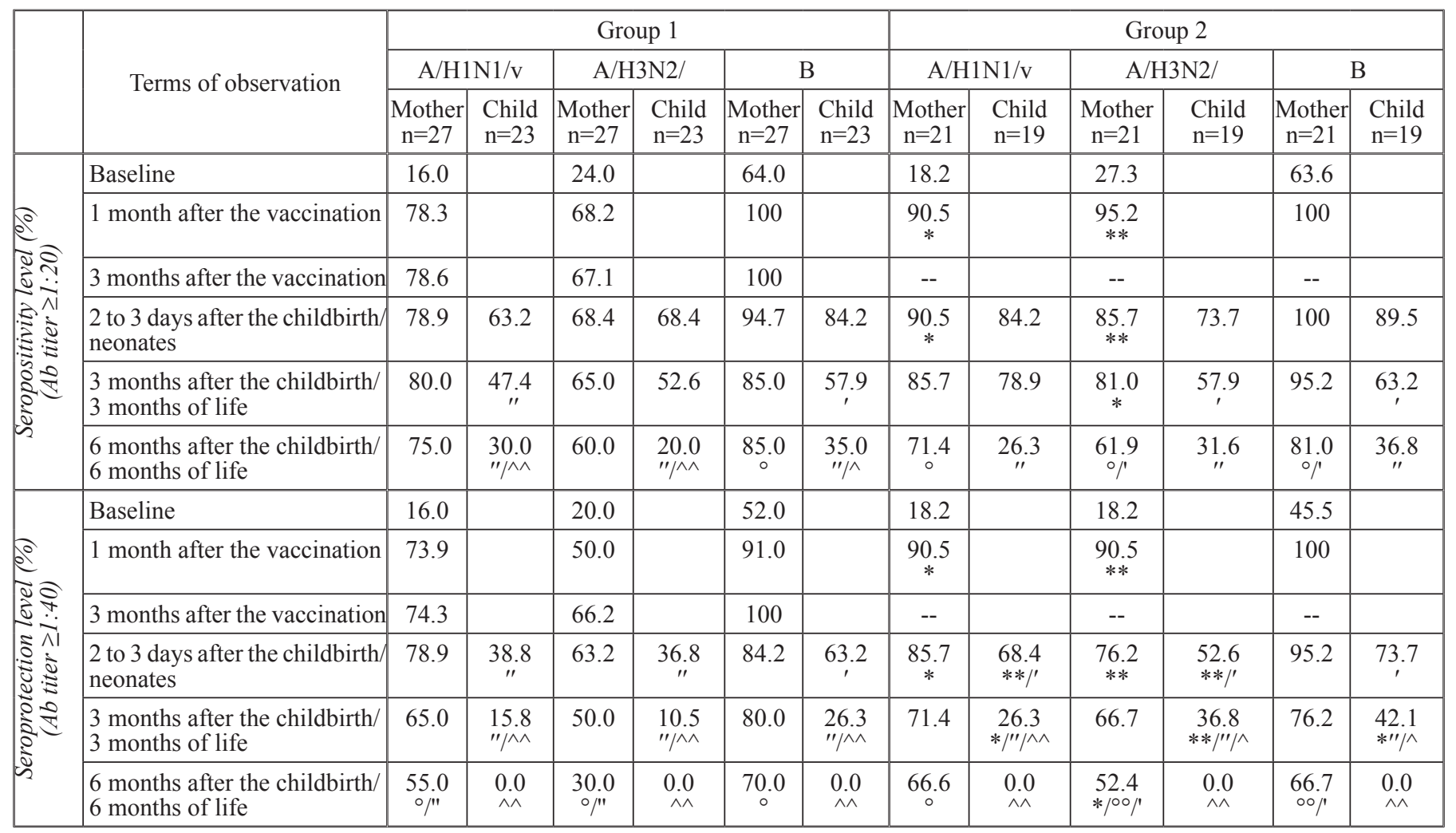

$*_{-} P<0.05$, **- $P<0.01$ - between the trimesters of vaccination; '- $P<0.05$, "- $P<0.01$ - between the mother-child groups; ${ }^{\circ}-P<0.05$, ${ }^{\circ}-P<0.01$ - within the group of women, between 1 month after the vaccination and 6 months after the childbirth; '- $P<0.05$, "- $P<0.01-$ within the group of women, between days 2 to 3 after the childbirth and 6 months after the childbirth; $\wedge_{-} P<0.05, \wedge_{-} P<0.01$ - within the group of children, in comparison with the baseline data at childbirth .

Assessing the seroprotection level in the dynamics after the vaccination, we can note that in women vaccinated against flu in the third trimester, the immune response to all the virus strains corresponded to the recommended CPMP criteria (Table 2). In pregnant women vaccinated in the second trimester against the $\mathrm{A} / \mathrm{H} 3 \mathrm{~N} 2 /$ strain, a level of $\mathrm{HAI}-\mathrm{Ab}$ within $\geq 1: 40$ was registered in $50 \%$. Subsequently ( 3 months after vaccination), this value slightly increased (66.2\%), $P>0.05$. Observation of women for 9 months in Group 1 and 7 months in Group 2 after the vaccination showed similar changes in the levels of HAI-Ab, with a significant reduction in those levels 6 months after childbirth. At the same time, the antibodies in the protective values to the tested strains of the flu virus in vaccinated women in the second and third trimesters were registered in $30 \%-70 \%$ and $52.4 \%-66.7 \%$ of cases. Moreover, by the mentioned date, significant differences in more pronounced loss of immune protection were identified only on the $\mathrm{A} / \mathrm{H} 3 \mathrm{~N} 2 /$ strain in pregnant women vaccinated in the third trimester.

By days 2 to 3 after childbirth, in children born to mothers of Group 1, HAI-Ab in the protective values to different strains of the flu virus were registered in $36.8 \%$ to $63.2 \%$ of cases, while in children born to mothers of Group 2, these indicators constituted $52.6 \%$ to $73.7 \%$ of persons. High $\mathrm{HAI}-\mathrm{Ab}$ values to all the strains of the flu virus in children of Group 2 were observed after 3 months. However, 6 months later in children of the observed groups we did not find any protective values of specific antibodies. Comparing the levels of seroprotection to the flu viruses in the mother-infant pairs, we can note that in children, antibodies having protective values at all the stages of the study were registered at a lower level than in their mothers, regardless of the trimester of vaccination.

The study of dynamics of the post-vaccination level of $\mathrm{HAI}-\mathrm{Ab}$ showed that one month after the vaccination in all the clinical groups there was a significant increase in GMTs, with high GMTR in the third trimester, especially against the A/ H3N2/ (Table 3). In pregnant women of Group 1, GMTs were in the same values 3 months after the vaccination $(P>0.05)$. By days 2 to 3 after childbirth ( 3 to 6 months after vaccination, in the second and third trimesters), significant differences in this parameter between the groups of women were identified only for the $\mathrm{A} / \mathrm{H} 3 \mathrm{~N} 2 /$, with the higher being those women who were vaccinated in the third trimester. Six months after childbirth in both groups, the level of GMTs reduced gradually.

In neonates on days 2 to 3 of life, GMTs were significantly lower than in their mothers, regardless of when the mothers were vaccinated. However, in children born to women of Group 2, the GMTs to the A/H1N1/ and A/H3N2/ flu strains were higher than in infants born to mothers of Group 1. The same feature can be traced against the A/H3N2/ at 3 months after childbirth. At the sixth month of life, there were no significant differences in GMTs. 
Table 3.

GMTs in the mother-child pairs depending on the trimester of vaccination of pregnant women against flu

\begin{tabular}{|c|c|c|c|c|c|c|c|c|c|c|c|c|}
\hline \multirow{3}{*}{$\begin{array}{l}\text { Terms of } \\
\text { observation }\end{array}$} & \multicolumn{6}{|c|}{ Group 1} & \multicolumn{6}{|c|}{ Group 2} \\
\hline & \multicolumn{2}{|c|}{$\mathrm{A} / \mathrm{H} 1 \mathrm{~N} 1 / \mathrm{v}$} & \multicolumn{2}{|c|}{ A/H3N2/ } & \multicolumn{2}{|c|}{ B } & \multicolumn{2}{|c|}{$\mathrm{A} / \mathrm{H} 1 \mathrm{~N} 1 / \mathrm{v}$} & \multicolumn{2}{|c|}{ A/H3N2/ } & \multicolumn{2}{|c|}{ B } \\
\hline & $\begin{array}{c}\text { Mother } \\
\mathrm{n}=27\end{array}$ & $\begin{array}{l}\text { Child } \\
\mathrm{n}=23\end{array}$ & $\begin{array}{c}\text { Mother } \\
n=27\end{array}$ & $\begin{array}{l}\text { Child } \\
\mathrm{n}=23\end{array}$ & $\begin{array}{c}\text { Mother } \\
\mathrm{n}=27\end{array}$ & $\begin{array}{l}\text { Child } \\
\mathrm{n}=23\end{array}$ & $\begin{array}{c}\text { Mother } \\
n=21\end{array}$ & $\begin{array}{l}\text { Child } \\
\mathrm{n}=19\end{array}$ & $\begin{array}{c}\text { Mother } \\
\mathrm{n}=21\end{array}$ & $\begin{array}{l}\text { Child } \\
\mathrm{n}=19\end{array}$ & $\begin{array}{c}\text { Mother } \\
\mathrm{n}=21\end{array}$ & $\begin{array}{l}\text { Child } \\
\mathrm{n}=19\end{array}$ \\
\hline Baseline & $\begin{array}{c}8.47 \\
\pm 0.24\end{array}$ & & $\begin{array}{c}8.47 \\
\pm 0.28\end{array}$ & & $\begin{array}{l}24.28 \\
\pm 0.29\end{array}$ & & $\begin{array}{l}10.00 \\
\pm 0.40\end{array}$ & & $\begin{array}{l}11.34 \\
\pm 0.54\end{array}$ & & $\begin{array}{l}21.30 \\
\pm 0.28\end{array}$ & \\
\hline $\begin{array}{l}1 \text { month after } \\
\text { the vaccination }\end{array}$ & $\begin{array}{l}66.77 \\
\pm 0.41\end{array}$ & & $\begin{array}{l}29.19 \\
\pm 0.40\end{array}$ & & $\begin{array}{l}124.35 \\
\pm 0.29\end{array}$ & & $\begin{array}{l}85.20 \\
\pm 0.62 \\
*\end{array}$ & & $\begin{array}{c}102.93 \\
\pm 0.62 \\
* *\end{array}$ & & $\begin{array}{c}160.0 \\
\pm 0.23 \\
*\end{array}$ & \\
\hline $\begin{array}{l}3 \text { months after } \\
\text { the vaccination }\end{array}$ & $\begin{array}{l}56.57 \\
\pm 0.55\end{array}$ & & $\begin{array}{l}27.04 \\
\pm 0.48\end{array}$ & & $\begin{array}{l}99.02 \\
\pm 0.29\end{array}$ & & -- & & -- & & -- & \\
\hline $\begin{array}{l}2 \text { to } 3 \text { days } \\
\text { after childbirth/ } \\
\text { neonates }\end{array}$ & $\begin{array}{l}48.00 \\
\pm 0.39\end{array}$ & $\begin{array}{l}18.59 \\
\pm 0.35 \\
, "\end{array}$ & $\begin{array}{l}26.78 \\
\pm 0.37\end{array}$ & $\begin{array}{l}16.66 \\
\pm 0.29\end{array}$ & $\begin{array}{l}69.14 \\
\pm 0.32\end{array}$ & $\begin{array}{c}30.98 \\
\pm 0.29 \\
\quad "\end{array}$ & $\begin{array}{l}42.60 \\
\pm 0.31\end{array}$ & $\begin{array}{c}29.19 \\
\pm 0.30 \\
* / /\end{array}$ & $\begin{array}{c}54.81 \\
\pm 0.62 \\
* * \\
\end{array}$ & $\begin{array}{c}33.11 \\
\pm 0.56 \\
* * / /\end{array}$ & $\begin{array}{l}66.22 \\
\pm 0.30\end{array}$ & $\begin{array}{c}37.03 \\
\pm 0.39 \\
\text { " }\end{array}$ \\
\hline
\end{tabular}

$*_{-} P<0.05, *_{-} P<0.01$ - between the trimesters of vaccination; '- $P<0.05, "$ - $P<0.01$ - between the mother-child groups; ${ }^{\circ}-P<0.05$, ${ }^{\circ}-P<0.01-$ within the group of women, between 1 month after the vaccination and 6 months after childbirth; '- $P<0.05$ - within the group of women, between days 2 to 3 after childbirth and 6 months after childbirth; $\wedge^{\wedge} P<0.05,{ }^{\wedge}-P<0.01$ - within the group of children, in comparison with the baseline data at childbirth

Dynamic observation of the vaccinated pregnant women makes it possible to note that the seroconversion rate and factor of the vaccine strains of the flu virus meet the CPMP criteria, with higher values among women in the third trimester. Differences are more pronounced in children whose mothers were vaccinated in the second trimester: antibodies to the $\mathrm{A} / \mathrm{H} 1 \mathrm{~N} 1 /$ strain have the value of $36.8 \%$, and antibodies to flu B have the value of $63.2 \%$, which was different from the same indicators in children born to women vaccinated in the third trimester $-68.4 \%(P<0.01)$ and $73.7 \%(P<0.05)$. There was a significant reduction in the level of transplacental antibodies that have protective values in both groups of children. By 3 months of age in Group1, the protective level of HAI-Ab to the flu A virus strains was observed in $10.5 \%$ to $15.8 \%$ of children and to the flu B virus it was observed in $26.3 \%$ of children, against $26.3 \%$ to $36.8 \%$ and $42.1 \%$ for the same strains for children in Group $2(P<0.05)$. Six months later, there were no protective HAI-Ab titers in the observed children. In this period, the immune protection against the flu viruses in women vaccinated in the second trimester was $30 \%$ to $55 \%$ to the flu A strains and $70 \%$ to the flu B strains against $52.4 \%$ to $66.6 \%$ and $66.7 \%$ in the group vaccinated in the third trimester. Significant differences between the groups in terms of the seroprotection level 6 months after childbirth were observed only for the A/H3N2/ $(P<0.05)$.

\section{Discussion}

The discovered differences in the production of specific antibodies to the flu viruses, depending on the trimester of vaccination, are not related to pregnancy disorders. This can be confirmed by the state of infants and children during the first months of life, which reflects the physiological development of infants and the lack of aggravated infectious history.

Despite the existing features in the formation of the immune protection against influenza, in both groups of pregnant women the ratio of increase in the protective values of antibodies (seroconversion rate and factor) met the CPMP criteria. At the same time, it should be noted that after the vaccination there was an increase by 1.5 to 3 times in the number of antibodies to the pandemic strain of $\mathrm{A} / \mathrm{H} 1 \mathrm{~N} 1 / \mathrm{v}$ of the flu virus. Vaccination with a subunit vaccine in the third trimester of pregnancy was accompanied by a more pronounced production of specific antibodies in comparison with vaccination at the earlier stages of gestation.

The study of serum showed that women who were vaccinated in the third trimester of pregnancy have a more pronounced seroprotection level in comparison with those who were vaccinated in the second trimester. Subsequently, 3 to 6 months after childbirth, the seroprotection level in latevaccinated women in the mother-child pairs was higher than in the group of those vaccinated earlier. Regardless of the time of vaccination, 6 months after childbirth there were no antibodies in protective titers in any child. However, if we take into account that the level of specific antibodies $\geq 1: 20$ may also have conditionally protective values, 6 months later they are found in $20 \%$ to $35 \%$ of children in Group 1 and in $26.3 \%$ to $36.8 \%$ of children in Group 2 with no significant difference depending on the time of vaccination during gestation.

GMTs in pregnant women vaccinated in the third trimester of gestation were higher than for women vaccinated in the second trimester. A significant decline in this value was observed 6 months after childbirth. Moreover, although the women in Group I were vaccinated 3 months earlier than those in Group 2, significant differences in GMTs disappeared within 6 months after childbirth (there were differences in GMTs 
only for the $\mathrm{A} / \mathrm{H} 3 \mathrm{~N} 2 /$, where this indicator in all the periods of observation was higher in women vaccinated at the later stages of pregnancy). In infants born to mothers vaccinated in the third trimester of pregnancy, there were more pronounced values of the GMTs to the strains of the flu A virus on day 2 to 3 of life, i.e. there was a direct correlation between the number of specific antibodies in children and the level of antibodies in their mothers. Three months later in children there were the same tendencies in the distribution of antibodies between the two groups to different strains of the flu virus during the overall decrease in the values of GMTs.

\section{Conclusion}

Thus, vaccination of women against flu with a subunit preparation of Agrippal S1 in both the second and third trimester of pregnancy has a sufficiently high efficacy. Vaccination of pregnant women in the third trimester, as opposed to the vaccination at the early stages of gestation, is accompanied by the increased production of HAI-Ab with a more pronounced transplacental transfer of maternal antibodies to the fetus. At the same time, the level of protection against all the strains of influenza virus in children born to mothers vaccinated in the third trimester of pregnancy was equal, on average, to $64.9 \%$. However, during the vaccination of pregnant women in the second trimester, this indicator in children was equal to only $46.3 \%$. Three months later, the number of children with protective values of antibodies decreased, on average, by 2 times, and for all the strains the decrease was $17.5 \%$ in Group 1 and $35.1 \%$ in Group 2.

It is important to discuss the issue of the significance of HAI-Ab seropositive titers $(\geq 1: 20)$ in the anti-infective protection against the flu virus, because in children of this age these titers are still determined on average, for all the strains of the virus, in $28.3 \%$ of children in Group 1 and $31.6 \%$ of children in Group 2. Perhaps, their presence in the body of a child somehow affects the child's resistance to the infection; at the same time, there is as yet no evidence for this assumption.

\section{References}

1. Zaman K, Roy E, Arifeen SE, Rahman M, Raqib R, Wilson $\mathrm{E}$, et al. Effectiveness of maternal influenza immunization in mothers and infants. N Eng J Med. 2008;359(15):1555-64.

2. Steinhoff MC, Omer SB, Roy E, Arifeen SE, Raqib R, Altaye $\mathrm{M}$, et al. Influenza immunization in pregnancy antibody responses in mothers and infants. $\mathrm{N}$ Eng $\mathrm{J}$ Med. 2010;362(17)):1644-6.

3. Zuccotti G, Pogliani L, Pariani E, Amendola A, Zanetti A. Transplacental antibody transfer following maternal immunization with a pandemic 2009 influenza A(H1N1) MF59-adjuvanted vaccine. JAMA. 2010;304(21):2360-1.

4. Eick AA, Uyeki TM, Klimov A, Hall H, Reid R, Santosham M, et al. Maternal influenza vaccination and effect of influenza virus infection in young infants. Arch Pediatr Adolesc Med 2011;165(2):104-11.

5. Order of the Ministry of Health and Social Development of the RF of October 2, 2009 No. 808n. On the Approval of the Order of Rendering Obstetric-Gynecologic Assistance. [Electronic resource]. http://www.bestpravo.ru/federalnoje/ hj-dokumenty/14v.htm.

6. Botina AV, Medvedeva TG, Neznanov NG. Ethical aspects of medical researches with the participation of women of reproductive age. Good Clinical Practice 2003;3:43-46.

7. Good Clinical Practice. National Standard of the Russian Federation, GOSTR 52379-2005/ Moscow, 2005. [Electronic resource]. http://www.medtran.ru/rus/trials/gost/52379-2005.htm 8. Recommendations on the Organization and Implementation of Vaccination of Pregnant Women and Maternity Patients against the Flu A Virus (H1N1): Informational letter No. 154/3108-07 of December 11, 2009 [Electronic resource]. http:// www.rosminzdrav.ru/docs/mzsr/letters/161.

9. Order of the Ministry of Health and Social Development of the RF of April 28, 2007 No.307. On the Standard of Dispensary (Routine) Observation over a Child during the First Year of Life. http://www.garant.ru/products/ipo/prime/doc/4084665/.

10. Note for guidance on harmonization of requirements for influenza vaccines (CPMP/BWP/214/96). http://www. ema.europa.eu/docs/en_GB/document_library/Scientific_ guideline/2009/09/WC500003945.pdf. 